\title{
DIAGNOSING THE PRODUCTIVITY EFFECT OF PUBLIC CAPITAL IN THE PRIVATE SECTOR
}

\author{
Chu-Ping C. Vijverberg \\ Wichita State University \\ W. Frank Barton School of Business \\ and \\ Wim P.M. Vijverberg \\ University of Texas at Dallas \\ School of Economic, Political and Policy Sciences
}

\section{INTRODUCTION}

The potential impact of public capital on private sector productivity has attracted much attention recently [Gramlich, 1994]. With U.S. data, Figure 1 illustrates the issue. It shows five-year centered moving averages of total factor productivity growth in manufacturing and of labor productivity growth in the nonfarm business sector in combination with annual changes in the stock of public capital. From the mid 1960s to the early $1980 \mathrm{~s}$, the gradual decline in total factor productivity and labor productivity growth rates was accompanied by a steady decrease in the growth in public capital. It seems therefore that the decrease in public capital growth is a candidate explanation for the decline in productivity growth that occurred in the 1970s. As Figure 1 also illustrates, however, it is much less clear whether fluctuations in the provision of public capital can account for the variation in productivity growth in the 1980s and 1990s: productivity growth has improved on a more consistent basis in the late 1990s, whereas, after dropping off even in the late 1960s, the growth in the public capital stock never really recovered.

Early econometric research [Ratner, 1983; Ram and Ramsey, 1989; Aschauer, 1989; Munnell, 1990] used time series data in a production function framework and found that public capital indeed contributed significantly to the decline of private productivity. Other researchers developed either profit function [Deno, 1988; Demetriades and Mamuneas, 2000] or cost function [Lynde and Richmond, 1992; Morrison and Schwartz, 1996; Rovolis and Spence, 2002] models and came to the same conclusion. ${ }^{1}$ Vijverberg, Vijverberg and Gamble [1997] used all three approaches but could not find any consistent productivity effect between them. The discrepancy between the findings may result from using time series of a different length (as well as implementing models in different ways): as is clear from Figure 1, a study that uses data up to the

Wim P. M. Vijverberg: University of Texas at Dallas, P.O. Box 830688, School of Economic, Political and Policy Sciences, Richardson, Texas 75083. E-mail: vijver@utdallas.edu. 
early 1980s is more likely to find a positive contribution than one that extends the time series into the 1990 s.

\section{FIGURE 1}

\section{Annual Growth Rates in Total Factor Productivity TFP, Labor Productivity $Q / L$ and Public Capital G}

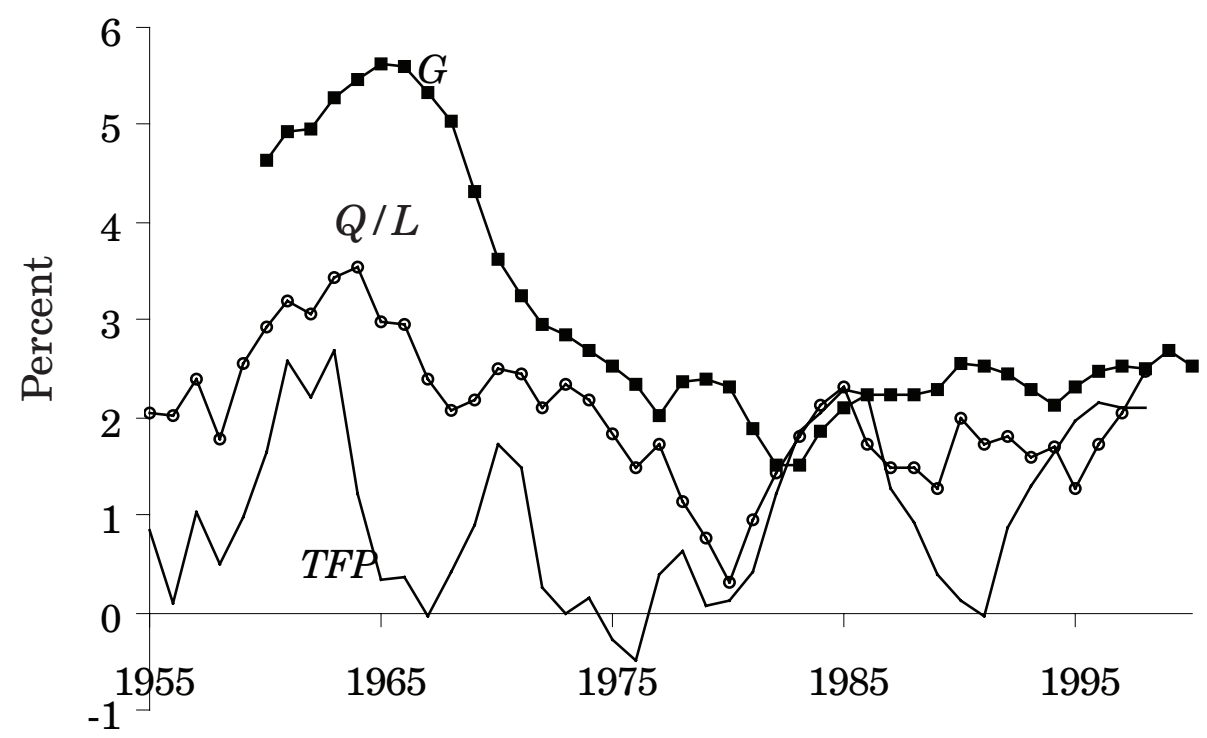

Note: TFP pertains to manufacturing, Q/L pertains to the nonfarm business sector, and $\mathrm{G}$ includes federal and state public capital. Growth rates in TFP and Q/L are presented by means of five-year centered moving averages.

In order to deal with the nonstationarity problem in time series variables, some studies used differenced variables in either time series [Tatom, 1991; Sturm and De Haan, 1995] or panel data [Garcia-Mila, McGuire and Porter, 1996]. These differenced variable models refuted the notion that public capital contributed to private sector productivity. However, some [Lynde and Richmond, 1993] estimated share equations in a profit function with consideration of nonstationarity in the time series data and found that public capital did contribute to private productivity. In all these studies, the focus is on either the whole private sector or the manufacturing sector.

These results have not been of much use to policy makers. Should they propose more investment in public capital? What is the rate of return $?^{2}$ Will it substitute for durable goods that the private sector would otherwise purchase itself? In the light of these questions, this paper reexamines the significance of public capital for the activity in the private sector and adds an analysis of its two major subsectors, namely, the manufacturing and service sectors. The underlying question is whether the productivity effect is concentrated in only one subsector. We utilize both cost function and profit function models to examine robustness. We address two issues that previous studies 
have given inadequate attention to. First, in these macroeconomic models one can hardly maintain the assumption that prices are exogenous. We employ instruments in order to account for the endogeneity of prices. Second, there are strong indications that most variables in the model are nonstationary. This raises questions about the statistical validity of the estimates. We generate diagnostics on the cost and profit models for each sector for both observed and instrumented prices; we also estimate these models with differenced data, although that is generally not a preferred method for dealing with nonstationarity. In the multiplicity of these diagnostics, we reconsider the impact of public capital.

With the various models we try to answer the following questions. How large is the marginal product of public capital? If public capital matters in private sector production, does it derive its impact mainly from the manufacturing or the service sector? Are results robust: do profit function and cost function approaches provide mutually consistent results? How soon will public capital investments raise labor productivity? Is public capital a substitute for or a complement of private capital and labor? Finally, do production functions exhibit constant returns to scale in the use of private and public capital [Barro, 1990; Rebelo, 1991]? Answers to these questions are valuable as one could argue that a sector benefiting more from public capital investments should contribute more to the payment for these investments—or be eligible for a less generous subsidy package to entice corporate relocation. Estimates of the elasticity of substitution are useful in predicting the impact of public capital investment on private investment and labor demand. Summarizing the many empirical results with a single statement, returns to investments in public capital appear to be sizable but cannot be estimated with precision due to the characteristics of the data.

The next section briefly outlines the theoretical models. The section after that describes the data and addresses estimation issues. The following section is the core of the paper, presenting various diagnostics of the relationships. Productivity effects and elasticities of substitution are reported in the next section. The final section concludes.

\section{THEORETICAL MODELS}

We examine the impact of public capital on private productivity with two different models: the cost function model and the profit function model. These models are based on the following production relationship:

$$
Q=F(L, K, G, t)
$$

where $Q$ is output, produced with inputs $L$ (labor), $K$ (capital), and $G$ (public capital), which we shall decompose into federal $\left(G_{f}\right)$ and state $\left(G_{s}\right)$ capital in most of our discussion. ${ }^{3}$ The variable $t$ represents the level of technology. $p_{I}$ denotes the price of $I$ for $I=Q, L, K$.

The change in labor productivity is computed by differentiating (1) totally with respect to $Q, K, L, G$ and $t$, and then rearranging terms. Thus, first we have 


$$
d Q=F_{L} d L+F_{K} d K+F_{G} d G+F_{t} d t
$$

Since $d(Q / L)=(Q / L)(d Q / Q-d L / L)$ and similarly $d(K / L)=(K / L)(d K / K-d L / L)$, it then follows that

$$
\begin{aligned}
\frac{d Q}{Q}-\frac{d L}{L} & =\frac{F_{K} K}{Q}\left(\frac{d K}{K}-\frac{d L}{L}\right)+\left(\frac{F_{L} L}{Q}+\frac{F_{K} K}{Q}-1\right) \frac{d L}{L}+\frac{F_{G} G}{Q} \frac{d G}{G}+\frac{F_{t}}{Q} d t \\
& \equiv \Delta_{K / L}+\Delta_{L}+\Delta_{G}+\Delta_{t}
\end{aligned}
$$

Thus, the proportional change in labor productivity is decomposed into four terms, related to the change in the capital/labor ratio, the size of the workforce, the provision of public capital, and a secular time trend. As indicated in equation (3), for simplicity of notation, $\Delta_{I}$ denotes the impact of $I$ on the change in labor productivity, with $I=K / L, L, G, t$. Let us also define $\Delta_{M F P}=\Delta_{G}+\Delta_{t}$ as multifactor productivity growth. The exact form of the expressions depends on whether the cost or profit function is used; see below. Note that the labor force effect $\Delta_{L}$ vanishes whenever the production process exhibits constant returns to scale with respect to $L$ and $K$.

\section{The Cost Function Model}

Let us define cost as [Lynde and Richmond, 1992; Morrison and Schwartz, 1996]: $C=p_{L} L+p_{K} K$. With competitive input markets and cost-minimizing behavior, $C$ is expressed as

$$
C=C\left(p_{L}, p_{K}, Q, G, t\right)
$$

Owing to cost minimization, we have $\partial C / \partial p_{I}=I$, for $I=L, K$. Define the cost share of input $I$ as $\sigma_{I}=p_{I} I / C$, which, again because of cost-minimizing behavior, can also be expressed as $\sigma_{I}=\partial \ln C / \partial \ln p_{I}$. Then, $\sigma_{L}+\sigma_{K}=1$. Furthermore, in competitive output markets, $\partial C / \partial Q$ equals $p_{Q}$, which implies that the "output share" $\sigma_{Q}=p_{Q} Q / C$ equals $\partial \ln C / \partial \ln Q$.

Assumptions of competitive output markets and cost-minimization yield $\partial C / \partial G=-p_{Q} F_{G}{ }^{4}$ and $\partial C / \partial t=-p_{Q} F_{t}$ and, of course, $p_{Q} F_{I}=p_{I}$ for $I=L, K$. Together with the definitions of $\sigma_{G}=\partial \ln C / \partial \ln G$ and $\sigma_{t}=\partial \ln C / \partial t$, we are able to rewrite Equation (3) describing the change in labor productivity in terms of $\sigma$-shares:

$$
\frac{d Q}{Q}-\frac{d L}{L}=\frac{\sigma_{K}}{\sigma_{Q}}\left(\frac{d K}{K}-\frac{d L}{L}\right)+\frac{1-\sigma_{Q}}{\sigma_{Q}} \frac{d L}{L}-\frac{\sigma_{G}}{\sigma_{Q}} \frac{d G}{G}-\frac{\sigma_{t}}{\sigma_{Q}} d t
$$

For estimation, we specify a translog cost equation (fully quadratic in logs and time trend, however, without $[\ln G]^{2}$ and $t[\ln G]$ to avoid extreme multicollinearity) and derive the labor share, capital share and output share equations from it, us- 
ing the information that the labor and capital shares sum to 1 . To be precise, let $x=\left(\begin{array}{llll}\ln p_{L}-\ln p_{K} & \ln Q & \ln G & t\end{array}\right)^{\prime}$. Then

$$
\begin{aligned}
& \ln C=\alpha+x^{\prime} \beta+0.5 x^{\prime} \Gamma x \\
& \sigma_{L}=\beta_{L}+\Gamma_{L .} x \\
& \sigma_{Q}=\beta_{Q}+\Gamma_{Q .} x
\end{aligned}
$$

where $\beta_{L}$ and $\beta_{Q}$ are the elements of the vector $\beta$ that are associated with $\ln p_{L}-\ln p_{K}$ and $\ln Q$ in the vector $x$, and where $\Gamma_{L}$ and $\Gamma_{Q}$ are similarly corresponding rows of the symmetric matrix $\Gamma{ }^{5}$ For internal consistency of the model, we impose the implied cross-equation parameters restrictions. ${ }^{6}$ Given additive disturbance terms, the three equations in (6) are estimated jointly, allowing for a full covariance matrix as well as first-order serial correlation (within each equation, not across equations).

\section{The Profit Function Model}

Profit is defined as [Deno, 1988; Lynde and Richmond, 1993] $\Pi=p_{Q} Q-p_{L} L-p_{K} K$. Assuming that input and output markets are competitive and that firms maximize profits, $\Pi$ can also be expressed as

$$
\Pi=\Pi\left(p_{Q}, p_{L}, p_{K}, G, t\right)
$$

where, under the stated assumptions, $\partial \Pi / \partial P_{Q}=Q$, and $\partial \Pi / \partial p_{I}=-I$ for $I=L, K$. Moreover, as increases in $G$ and $t$ do not contribute to costs, we have $\partial \Pi / \partial G=p_{Q} F_{G}$, and $\partial \Pi / \partial t=$ $p_{Q} F_{t}$. Let us then define "profit ratios" as $s_{I} \equiv p_{I} I / \Pi$ for $I=Q, L, K$. These quantities are measurable with the economic data we utilize later on and, under the stated conditions, relate to the profit function as $s_{Q}=\partial \ln \Pi / \partial \ln p_{Q},-s_{I}=\partial \ln \Pi / \partial \ln p_{I}$ for $I=L, K$. Moreover, since profit equals revenue minus costs, we have $s_{Q}-s_{L}-s_{K}=1$. Finally, defining $s_{G}=$ $\partial \ln \Pi / \partial \ln G$ and $s_{t}=\partial \ln \Pi / \partial t$, the change in labor productivity is given by

$$
\frac{d Q}{Q}-\frac{d L}{L}=\frac{s_{K}}{s_{Q}}\left(\frac{d K}{K}-\frac{d L}{L}\right)-\frac{1}{s_{Q}} \frac{d L}{L}+\frac{s_{G}}{s_{Q}} \frac{d G}{G}+\frac{s_{t}}{s_{Q}} d t
$$

We specify a translog function, again without $[\ln G]^{2}$ and $t[\ln G]$. From this, we derive equations for $s_{Q}$ and $s_{L}$, once again using information about the restriction on the values of these shares.

$$
\begin{aligned}
& \ln \Pi=\theta+z^{\prime} \kappa+0.5 z^{\prime} \Lambda z \\
& s_{Q}=\kappa_{Q}+\Lambda_{Q .} z \\
& -S_{L}=\kappa_{L}+\Lambda_{L .} z
\end{aligned}
$$


Here, $z=\left(\ln p_{L}-\ln p_{K} \ln p_{Q}-\ln p_{K} \ln G t\right) . \kappa$ is a parameter vector, elements of which are used in the two share equations, and $\Lambda$ is a symmetric matrix with $\Lambda_{G G}=$ $\Lambda_{G t}=\Lambda_{t G}=0$. We assume additive disturbance terms with a full covariance matrix, subject to first-order serial correlation within each equation; the serial correlation coefficients for the $s_{Q}$ and $-s_{L}$ equations are restricted to be the same, in view of the adding-up constraint [Berndt and Savin, 1975]. For internal consistency of the model, cross-equation parameter restrictions are imposed.

\section{DATA AND ESTIMATION ISSUES}

\section{The Data}

The data consist of annual time series for the nonfinancial corporate sector (which we shall refer to as the "nfc private" sector) from 1959 to 2000, manufacturing sector from 1959 to 2000, and service sector from 1965 to $2000^{7}$ in the United States. The manufacturing sector includes both durable and nondurable goods. The service sector, as we define it for this paper, contains wholesale and retail trade, and services (as defined as such in our sources). We specifically omit the subsectors of finance, insurance, and real estate, which, in most other discussions, are typically included in the definition of the service sector. We found that these subsectors employ around ten percent of the workers of the overall aggregate but utilize nearly seventy percent of the nonresidential capital: in particular, real estate services are capital-intensive. This suggests heterogeneity in the service sector: it is better to drop real estate. Unfortunately, information on labor in real estate services is not separated from that in finance and insurance services.

Public capital $(G)$ refers to net stock of (nonmilitary) equipment and structures in the hands of federal (denoted as $\left(G_{f}\right)$ and state and local $\left(G_{s}\right)$ government, with $G=G_{f}+G_{s}$. Detailed information about definitions and sources is given in Appendix A.

While we analyze both the total and the sectoral impact of public capital, it should be noted that the sector definitions imply some slippage. Specifically, the nonfinancial corporate private sector extends beyond manufacturing and service activities, and the manufacturing and service sectors include noncorporate private business activity. Nevertheless, we choose to work with these private sector data for two reasons: $(i)$ a shorter series (1959-1989) of these nfc private sector data have been used in other studies [Lynde and Richmond, 1992; 1993; Vijverberg, Vijverberg and Gamble, 1997], so that there is a strong link of comparison with previous research; and (ii) for the nfc private sector, labor and output data come from the same source, (implying data consistency), whereas sectoral data derive from several sources and sectoral labor specifically excludes supervisory personnel. But while there are differences, there is also much overlap. ${ }^{8}$ Therefore, acknowledging that it is desirable but extremely difficult to develop sectorally consistent data for all variables of all subsectors, we conclude that a study of our three samples contributes to an understanding of the source of the productivity effect, if any, of public capital in the private sector. 


\section{Estimation Issues}

Under the cost and profit approaches, the empirical model consists of a system of three equations, two of which are share/ratio equations. These three equations are estimated jointly using the Full Information Maximum Likelihood (FIML) technique, allowing for a full covariance matrix as well as first-order serial correlation.

To examine robustness of the model, we estimate the models with aggregated as well as disaggregated public capital and with measured (or observed) as well as instrumented price variables. Given the size of the sectors in the overall economy, one might argue that price variables cannot be taken as exogenous. ${ }^{9}$ To create the instrumented price variables, we use the following instruments: the federal funds rate, Romer dates [Romer and Romer, 1990; 1994], real defense spending, lagged private capital stock and labor force, and real exports, and lags of several of these. The first two of these represent the impact of government monetary policy; defense spending is driven by political cycles; the lagged values are predetermined factors impacting the current economy; and the demand for U.S. exports originates from conditions abroad. The instrumental equations have $R^{2}$-values ranging from 0.933 to 0.998 , with the $\ln \left(p_{k}\right)$ variable being the hardest to predict well. ${ }^{10}$ Further tests soundly reject any presence of unit roots in the residuals of the instrumental equations and thus indicate the existence of cointegrating relationships. It should be noted that the IV approach to the cost and profit function models has desirable properties only asymptotically and that the results for samples as small as those used here must be interpreted with some caution.

\section{DIAGNOSTICS}

We evaluate the influence of public capital on private sector productivity from three different angles. First, because of the threat that nonstationarity in the data poses to the quality of the parameter estimates, all variables in each model are tested for nonstationarity: the logarithm of prices in each sector, the logarithm of public capital, the labor and output shares and ratios, and the logarithm of cost and profit. Three separate tests are used to determine the existence of nonstationarity: the $Z_{\rho}$ and $Z_{t}$ tests of Phillips and Ouliaris [1990], and the Augmented Dickey-Fuller (ADF) test as modified by Elliott, Rothenberg and Stock [1996] with a lag selected according to the Schwarz information criterion. The first two tests indicate nonstationarity for all variables with the possible exception of $\ln G$ and $\ln G_{s}$ and, for the nfc private sector data, the ratio variables $s_{L}$ and $s_{Q}{ }^{11}$ The modified ADF test also indicates stationarity for $\ln \Pi$ in the nfc private sector and in manufacturing, and for $s_{L}$ and $s_{Q}$ in the service industry.

Concerns of possible spurious regression results thus arise. We therefore test the residuals of all models in all three sectors for nonstationarity by means of the ElliottRothenberg-Stock [1996] and the Phillips-Ouliaris [1990] $Z_{\rho}$ and $Z_{t}$ tests, evaluated with critical values that are simulated for each given sample size since asymptotic critical values may be seriously misleading when applied to finite samples [Davidson 
and MacKinnon, 1993, 721]. It turns out that, for all cases except the nfc private sector, the hypothesis that residuals are nonstationary cannot be rejected even at the 10 percent significance level, raising doubts as to whether the models capture production relationships in the data. However, should this result be taken at face value? First, there is much debate about the power of most tests in distinguishing between unit root and stationary processes in finite-sample observations [Hamilton, 1994, 444-446]. This is particularly true when the sample is small, as it is here. For example, by means of a simulation we found that in a case where disturbances were actually stationary and followed an $\mathrm{AR}(1)$ process with a correlation coefficient of 0.5 , the probability of concluding in favor of cointegration would be only about one third: the power of the test for cointegration is low indeed. Moreover, the autocorrelation and partial autocorrelation functions of the residuals of the cost and profit function models indicate cases where mild serial correlation is evident but a unit root is highly implausible. ${ }^{12}$ Second, here is a case where the econometric test statistics, though sophisticated in themselves, are primitive in comparison to the microeconometric cost and profit function model. The test statistics used here are supposed to apply to residuals of a linear OLS model with unit root variables; our microeconometric model consists of a set of interrelated equations with cross-equation parameter restrictions, is estimated with FIML, and contains squared values of variables that have unit roots. For such a model, suitable econometric test statistics do not exist. For these reasons, the apparent outcome of the cointegration tests cannot be considered conclusive. ${ }^{13}$ We must probe further.

The second diagnostic is the likelihood ratio test that verifies the significance of public capital in the model. Removing public capital from the entire model yields likelihood ratio test statistics reported in Table 1, panel A; these are to be compared against the critical value $\chi_{0.95}^{2}(3)=7.81$ for the aggregate public capital model and $\chi_{0.95}^{2}(6)=12.59$ for the disaggregate public capital model, under the presumption that the finite-sample likelihood ratio statistic has a distribution approximating the asymptotic $\chi^{2}$-distribution. The likelihood ratio tests indicate that public capital is a significant factor in cost function models in all three sectors and in the profit function model in the nfc private sector. ${ }^{14}$

The last diagnostic of the impact of public capital on the private sector is its estimated return, which indicates the economic significance of public capital's contribution. This return is computed as the marginal product of $G$, i.e., $F_{G}$ according to the production function specified in equation (1), where both $G$ and $Q$ are specified in real terms - see also Appendix C. $F_{G}$ indicates the increase in annual private sector production in billions of dollars when the stock of public capital rises by $\$ 1$ billion. Thus, $F_{G}$ measures the payoff of an investment in public capital. Table 1, panel B, reports returns calculated for average values of the explanatory variables of the model. ${ }^{15}$ The estimated return to aggregate public capital varies between 14 and 91 percent per annum in the cost models and between -34 and 14 percent in the profit models. ${ }^{16}$ The estimated return to federal public capital falls between -48 percent and 101 percent per annum, while the range for state public capital is wider yet, from -68 to 314 percent. The profit function approach yields most of the estimated negative returns. 
TABLE 1

Diagnostics

A: Likelihood Ratio Test of Significance of Public Capital in the Model ${ }^{\text {a }}$

\begin{tabular}{llrrrrrr} 
& Treatment & \multicolumn{2}{c}{ NFC Private } & \multicolumn{2}{c}{ Manufacturing } & \multicolumn{2}{c}{ Services } \\
Model & of Prices & $\mathbf{A}^{\mathbf{b}}$ & $\mathbf{D}^{\mathbf{b}}$ & $\mathbf{A}$ & $\mathbf{D}$ & \multicolumn{1}{c}{$\mathbf{A}$} & $\mathbf{D}$ \\
\hline Cost & Observed & 17.5 & 20.7 & $9.3^{\mathrm{c}}$ & $11.3^{\mathrm{c}}$ & $18.9^{\mathrm{c}}$ & $22.0^{\mathrm{c}}$ \\
& Instrumented & 7.2 & 8.2 & 4.4 & 13.7 & $14.7^{\mathrm{c}}$ & $16.0^{\mathrm{c}}$ \\
Profit & Observed & 25.8 & 33.8 & $2.0^{\mathrm{c}}$ & $4.8^{\mathrm{c}}$ & $0.6^{\mathrm{c}}$ & $2.8^{\mathrm{c}}$ \\
& Instrumented & 25.2 & 27.4 & 1.9 & 7.8 & 7.7 & 9.9
\end{tabular}

B: Estimated Return to (or Marginal Product of) Public Capital

\begin{tabular}{|c|c|c|c|c|c|c|c|c|}
\hline \multirow[b]{2}{*}{ Model } & \multirow{2}{*}{$\begin{array}{l}\text { Treatment } \\
\text { of Prices }\end{array}$} & \multirow{2}{*}{$\begin{array}{l}\text { Type of } \\
\text { Public Capital }\end{array}$} & \multicolumn{2}{|c|}{ NFC Private } & \multicolumn{2}{|c|}{ Manufacturing } & \multicolumn{2}{|c|}{ Services } \\
\hline & & & $\mathbf{F}_{G}$ & (St.dev.) & $\mathbf{F}_{\mathrm{G}}$ & (St.dev.) & $\mathbf{F}_{G_{\mathrm{G}}}$ & (St.dev.) \\
\hline \multirow[t]{2}{*}{$\overline{\text { Cost }}$} & Observed & Aggregate & 48 & (10) & 14 & (6) & 32 & (14) \\
\hline & Instrumented & Aggregate & 79 & (26) & 22 & (11) & 91 & (29) \\
\hline \multirow[t]{2}{*}{ Profit } & Observed & Aggregate & 2 & (10) & 0 & (10) & 15 & (21) \\
\hline & Instrumented & Aggregate & -34 & (28) & -10 & (7) & -13 & (13) \\
\hline \multirow[t]{2}{*}{ Cost } & Observed & Federal & 49 & (13) & 10 & (10) & 18 & (19) \\
\hline & Instrumented & Federal & 101 & (68) & 6 & (21) & 63 & (39) \\
\hline \multirow[t]{2}{*}{ Profit } & Observed & Federal & -33 & (23) & 0 & (16) & 13 & (25) \\
\hline & Instrumented & Federal & -48 & (104) & -26 & (23) & -26 & (17) \\
\hline \multirow[t]{2}{*}{ Cost } & Observed & State & 64 & $(93)$ & -33 & (52) & 158 & (139) \\
\hline & Instrumented & State & -68 & (378) & 104 & (117) & 474 & (343) \\
\hline \multirow[t]{2}{*}{ Profit } & Observed & State & 407 & (190) & 29 & (103) & 23 & (172) \\
\hline & Instrumented & State & 314 & (857) & 18 & (125) & 206 & (636) \\
\hline
\end{tabular}

Notes:

a Critical values are $\chi_{0.95}^{2}(3)=7.81$ for the aggregate public capital model and $\chi_{0.95}^{2}(6)=12.59$ for the disaggregate public capital model.

b "A" denotes that the model contains public capital in its aggregate measure; " $D$ " denotes that public capital appears in its disaggregate form.

c One or more of the first-order serial correlation coefficients in either the restricted or unrestricted models was set equal to 0.95 .

A few more notes about panel B are in order. First, generally, the imprecision in these estimates is substantial: for less than half of the estimated returns in panel $\mathrm{B}$ is the return greater than twice the standard deviation. This stands somewhat in contrast with panel A, according to which public capital matters. Still, most often the estimated return is positive. Second, in principle, the returns in the various separate sectors are to be added together in order to get a measure of benefit to the overall private sector: one would hope that the first column is roughly the sum of the second and third. However, even when allowing for the uncertainty in the estimated returns, the three columns in panel B of Table 1 are not quite consistent with each other. Third, cost models with instrumented prices often generate higher returns but profit models with instrumented prices often yield lower return estimates. In other words, it is not clear that endogeneity bias pushes the estimated returns one way or the other.

Table 1 allows us to argue that public capital matters. However, when variables are nonstationary, some might also consider differencing the data before estimating 
the relation in order to guard against the possibility of spurious regression [Tatom, 1991; Hamilton, 1994, 562; Strum and De Haan, 1995; Garcia-Mila, McGuire, and Porter, 1996], ${ }^{17}$ but we view this rather as a useful method to gain insight into shortrun reactions to changes in public capital. In the context of this paper, the process of estimating a model in first differences requires some further explanation. First of all, consider a generic equation $y=a_{0}+a_{1} x+a_{2} x^{2}$. In differenced form, this equation changes into $\Delta y=a_{1} \Delta x+a_{2}(2 x \Delta x)$; that is, the equation loses its intercept and shows $\Delta x$ and $2 x \Delta x$ on the right hand side. Applying this to the present situation, recall that both the cost and the profit function are specified as translog functions, which are quadratic in logarithms, and that the share/ratio equations are formulated as derivatives of these translog functions. When the model is estimated in first difference, each equation loses its intercept. However, the intercepts of the share/ratio equations (in levels) are still identified as slopes in the cost/profit equation. Moreover, when specified in first difference, the cost and profit equations contain products of level and first difference terms as a consequence of the quadratic terms in the translog form. For the cost model, for example, all of this implies

$$
\begin{aligned}
& \Delta \ln C=\beta^{\prime} \Delta x+0.5\left(x^{\prime} \Gamma \Delta x+\Delta x^{\prime} \Gamma x\right)=\beta^{\prime} \Delta x+x^{\prime} \Gamma \Delta x \\
& \Delta \sigma_{L}=\Gamma_{L .} \Delta x \\
& \Delta \sigma_{Q}=\Gamma_{Q .} \Delta x
\end{aligned}
$$

where the second equality of the first line follows from the symmetry of $\Gamma$. Thus, where the levels model specifies $\left(\ln p_{L}\right)^{2}$, the difference model contains $2\left(\ln p_{L}\right) \Delta \ln p_{L}$, and crossproduct terms like $\left(\ln p_{L}\right)\left(\ln p_{Q}\right)$ are replaced by $\left(\ln p_{L}\right) \Delta \ln p_{Q}+\left(\ln p_{Q}\right) \Delta \ln p_{L}$.

The diagnostics of models with differenced data are summarized in Table 2. Panel A of Table 2 presents the results of cointegration tests on the residuals of various models. ${ }^{18}$ For cost models, the hypothesis of nonstationary residuals is rejected, and for profit models this hypothesis is in doubt. ${ }^{19}$ Panel B shows that in more than half of the cases the likelihood ratio test fails to show that public capital matters.

The estimated returns to public capital take on both positive and negative values that are large and unreasonable (panel C). Since the standard errors of the returns to public capital are also very high, the returns are actually not statistically different from 0 . What is the economic meaning of this? A difference model presumes that a current change in the stock of public capital has a current (same-year, short-run) impact on the productive activity of the private sector. Given the length of the planning-and-investment period, it is not surprising that public capital has no impact on the private sector in the short run. In this sense, Table 2 confirms a reasonable $a$ priori notion about the impact of public capital - although it would have been more reassuring if panel $\mathrm{C}$ would have shown small and insignificant values. 
TABLE 2

Diagnostics of Models with Differenced Data

A: Unit Root Tests: Elliott-Rothenberg-Stock ADF, Phillips-Ouliaris $\mathrm{Z}_{\rho}$ and $\mathrm{Z}_{\mathrm{t}}$, and ACF

\begin{tabular}{|c|c|c|c|c|c|c|c|c|}
\hline \multirow[b]{2}{*}{ Model } & \multirow{2}{*}{$\begin{array}{l}\text { Treatment } \\
\text { of Prices }\end{array}$} & \multirow{2}{*}{$\begin{array}{c}\text { Tested } \\
\text { Equation }\end{array}$} & \multicolumn{2}{|c|}{ NFC Private } & \multicolumn{2}{|c|}{ Manufacturing } & \multicolumn{2}{|c|}{ Services } \\
\hline & & & $\mathbf{A}^{\mathbf{b}}$ & $\mathbf{D}^{\mathbf{b}}$ & $\mathbf{A}$ & D & $\mathbf{A}$ & D \\
\hline$\overline{\text { Cost }}$ & Instrumented & $\Delta(\ln C)$ & Sss0 & Sss0 & Sss0 & Sss0 & SsSA & SsSU \\
\hline & & $\Delta\left(\sigma_{\mathrm{L}}\right)$ & SSS0 & SSS0 & SSS0 & SSS0 & SSSA & SSSU \\
\hline & & $\Delta\left(\sigma_{Q}\right)$ & SSS0 & SSS0 & SSS0 & SSS0 & SSSA & SSSU \\
\hline Profit & Instrumented & $\Delta(\ln \Pi)$ & SUU0 & SUU0 & sUU0 & sUU0 & SUU0 & UUU0 \\
\hline & & $\Delta\left(-\mathrm{s}_{\mathrm{L}}\right)$ & SSS0 & SSS0 & Sss0 & SUU0 & SUUA & UUUA \\
\hline & & $\Delta\left(-\mathrm{s}_{\mathrm{Q}}^{\mathrm{L}}\right)$ & SSS0 & SSS0 & ssU0 & SUU0 & SUU0 & sUU0 \\
\hline
\end{tabular}

B: Likelihood Ratio Test of Significance of Public Capital in the Model

\begin{tabular}{llcccccc} 
& Treatment & \multicolumn{2}{c}{ NFC Private } & \multicolumn{3}{c}{ Manufacturing } & \multicolumn{3}{c}{ Services } \\
Model & of Prices & A & D & A & D & A & D \\
\hline Cost & Instrumented & 6.0 & 10.2 & 2.1 & 5.3 & 13.2 & 13.4 \\
Profit & Instrumented & 1.1 & 14.2 & 4.4 & 13.3 & 10.4 & 11.7
\end{tabular}

\section{C: Estimated Return to (or Marginal Product of) Public Capital}

\begin{tabular}{|c|c|c|c|c|c|c|c|c|}
\hline \multirow[b]{2}{*}{ Model } & \multirow{2}{*}{$\begin{array}{l}\text { Treatment } \\
\text { of Prices }\end{array}$} & \multirow{2}{*}{$\begin{array}{l}\text { Type of } \\
\text { Public Capital }\end{array}$} & \multicolumn{2}{|c|}{ NFC Private } & \multicolumn{2}{|c|}{ Manufacturing } & \multicolumn{2}{|c|}{ Services } \\
\hline & & & $\mathbf{F}_{G}$ & (St.dev.) & $\mathbf{F}_{G}$ & (St.dev.) & $\mathbf{F}_{\mathrm{G}}$ & (St.dev.) \\
\hline Cost & Instrumented & Aggregate & 161 & (93) & 44 & (34) & -1142 & $(2732)$ \\
\hline Profit & Instrumented & Aggregate & -74 & (71) & -30 & (15) & -43 & (14) \\
\hline Cost & Instrumented & Federal & 301 & (166) & 114 & (55) & -1240 & (3801) \\
\hline Profit & Instrumented & Federal & -40 & (87) & -26 & (17) & -53 & (26) \\
\hline Cost & Instrumented & State & -1055 & $(966)$ & -466 & $(457)$ & -3410 & (12073) \\
\hline Profit & Instrumented & State & -344 & $(590)$ & -49 & (118) & 81 & $(233)$ \\
\hline
\end{tabular}

Notes:

a Each cell in Panel A contains four indicators of unit root tests, associated with the Augmented DickeyFuller test as modified by Elliott-Rothenberg-Stock [1996], the $\mathrm{Z}_{\rho}$ and $\mathrm{Z}_{\mathrm{t}}$ tests of Phillips and Ouliaris [1990], and an evaluation of the autocorrelation function, respectively. For the first three, "U" denotes that the hypothesis that a unit root is present in the residual under test is not rejected, while "S" and "s" indicates stationarity (rejection of the unit root hypothesis) at a 5 and 10 percent significance level, respectively. For the last element of each cell, which pertains to ACF, "U" denotes evidence of unit root behavior in the autocorrelation function, "A" indicates some sort of an ARMA structure, and " 0 " stands for pure white noise.

b "A" denotes that the model contains public capital in its aggregate measure; "D" denotes that public capital appears in its disaggregate form

c $\quad$ Critical values are $\chi_{0.95}^{2}(3)=7.81$ for the aggregate ("A") public capital model and $\chi_{0.95}^{2}(6)=12.59$ for the disaggregate ("D") public capital model.

\section{LABOR PRODUCTIVITY EFFECTS, SUBSTITUTION ELASTICITIES, AND RETURNS TO SCALE}

What do these results say about the degree to which the provision of public capital is related to changes in the growth rate of labor productivity in the U.S.? As stated at the end of the previous section, public capital has no short-run effect. To understand 
long-run effects, we need to use the instrumented models in their level form, on the presumption $(i)$ that cointegration is present and the estimated relationship is not spurious, and (ii) that the instrumentation has effectively dealt with the simultaneity of prices. Why is it reasonable to proceed in this way? As argued before, the cointegration test statistics have low power. Failure to reject the Null hypothesis of nonstationarity in the residuals does not make the Null hypothesis true, and therefore the alternative hypothesis that cointegration exists is not disproved. Given their low power, cointegration tests can prove little statistically; ${ }^{20}$ therefore, we proceed on the grounds that economic theory guides us into the right direction, towards a valid model, which in our case is a cost function and a profit function model. Estimates of the models that use disaggregated public capital are presented in Appendix B.

Panel A of Table 3 shows the average contribution ${ }^{21}$ of public capital over the period 1990-2000, when labor productivity growth accelerated. Focusing on the earlier productivity slowdown, Panel B considers the change in contribution from 1960-197322 to 1976-1989, avoiding the turbulent years of 1974/75 right after the first oil crisis. To put these statistics in context, the observed annual change in labor productivity between 1990 and 2000 was 1.92 percent for the private sector, 3.40 percent for the manufacturing sector, and 1.02 percent for the service sector. Thus the figure in the private sector is roughly a weighted average of the figures of manufacturing and service sectors, as we already surmised in the section on Data and Estimation Issues. Both the cost function and the profit function models predict the total change in labor productivity fairly well. To relate this more specifically to Table 3.A, consider the nonfinancial corporate (nfc) private sector. While, as mentioned, labor productivity rose by 1.92 percent per year, the cost function model with aggregate public capital predicts a 2.17 percent rise (not shown in the table). This consists of 0.20 percent due to changes in the capital labor ratio $K / L,-0.41$ percent due to the changing size of the work force $L$, and 2.25 percent change in multifactor productivity, of which 2.11 percent comes from the increasing provision of public capital and 0.14 percent from technological growth as measured by the time trend. For brevity's sake, only the values of 2.25 and 2.11 are reported in Table 3 .

According to Table 3.A, all but one of the cost approach estimates suggest that public capital raises private sector productivity; however, the profit approach estimates for total and federal public capital indicate the opposite result. But the estimates are noisy. In fact, none of the profit approach estimates exceeds twice the standard error. Under the cost function approach, all of the estimates for aggregate capital are positive and statistically significantly different from zero. ${ }^{23}$

Given the concurrent decline in both public capital provision and private sector productivity in the 1970's, can we assert that the productivity decline is caused by the reduction in public capital investment? Table 3.B addresses this question. The observed difference in the average annual labor productivity growth between 19601973 and 1976-1989 was -1.27 percent for the private sector, 0.21 percent for the manufacturing sector, and -0.63 percent for the service sector. The predicted differences range from -0.62 to $-1.48,-0.37$ to 0.66 , and -1.81 to 0.31 percent for the three sectors respectively (not shown in Table 3.B). There are indications that total factor productivity went down and that aggregate public capital had something to do with 
it (second and third columns of Table 3.B), a further decomposition becomes murkier. With the switching signs and quite large standard errors, there is not enough support for the notion that the declining provision of public capital since the 1970s has contributed to the decline in labor productivity growth.

\section{TABLE 3}

\section{Effect of Public Capital on Labor Productivity ${ }^{\mathrm{a}}$}

\section{A: Average Predicted Annual Effect on Labor Productivity, 1990-2000}

\begin{tabular}{|c|c|c|c|c|c|c|}
\hline Sector & Obs. $^{b}$ & $\Delta_{M F P}$ & $\Delta_{G}$ & $\Delta_{M F P}$ & $\Delta_{G f}$ & $\Delta_{G s}$ \\
\hline \multicolumn{7}{|c|}{ Cost function approach (Instrumented Prices) } \\
\hline NFC Private & 1.92 & 2.25 & 2.11 & 2.12 & -0.01 & $\begin{array}{c}2.04 \\
(130)\end{array}$ \\
\hline Manufacturing & 3.40 & 3.31 & 1.75 & 3.18 & 0.51 & $\begin{array}{c}0.94 \\
(1.25)\end{array}$ \\
\hline Services & 1.02 & $\begin{array}{c}2.38 \\
(0.38)\end{array}$ & $\begin{array}{c}2.87 \\
(0.96)\end{array}$ & $\begin{array}{c}2.35 \\
(0.38)\end{array}$ & $\begin{array}{c}2.23 \\
(1.59)\end{array}$ & $\begin{array}{c}2.35 \\
(1.27)\end{array}$ \\
\hline \multicolumn{7}{|c|}{ Profit function approach (Instrumented Prices) } \\
\hline NFC Private & 1.92 & $\begin{array}{c}1.59 \\
(0.30)\end{array}$ & $\begin{array}{l}-3.17 \\
(2.57)\end{array}$ & $\begin{array}{c}1.65 \\
(0.33)\end{array}$ & $\begin{array}{l}-2.91 \\
(7.31)\end{array}$ & $\begin{array}{c}2.27 \\
(8.01)\end{array}$ \\
\hline Manufacturing & 3.40 & $\begin{array}{c}2.49 \\
(0.29)\end{array}$ & $\begin{array}{l}-1.51 \\
(1.21)\end{array}$ & $\begin{array}{c}2.06 \\
(0.39)\end{array}$ & $\begin{array}{l}-2.56 \\
(1.44)\end{array}$ & $\begin{array}{c}-0.12 \\
(1.81)\end{array}$ \\
\hline Services & 1.02 & $\begin{array}{c}1.47 \\
(0.09)\end{array}$ & $\begin{array}{l}-0.50 \\
(0.59)\end{array}$ & $\begin{array}{c}1.53 \\
(0.17)\end{array}$ & $\begin{array}{l}-0.95 \\
(0.81)\end{array}$ & $\begin{array}{c}1.08 \\
(3.06)\end{array}$ \\
\hline
\end{tabular}

B: Difference in the Average Annual Effect on Labor Productivity between 1960-1973 and 1976-1989

\begin{tabular}{|c|c|c|c|c|c|c|}
\hline Sector & Obs. $^{b}$ & $\Delta_{M F P}$ & $\Delta_{G}$ & $\Delta_{M F P}$ & $\Delta_{G f}$ & $\Delta_{G s}$ \\
\hline \multicolumn{7}{|c|}{ Cost function approach (Instrumented Prices) } \\
\hline NFC Private & -1.27 & -1.40 & -1.79 & -0.94 & 0.59 & $\begin{array}{l}-2.06 \\
(1.88)\end{array}$ \\
\hline Manufacturing & 0.21 & $\begin{array}{l}-0.51 \\
(0.47)\end{array}$ & $\begin{array}{l}-0.87 \\
(0.76)\end{array}$ & $\begin{array}{l}-0.85 \\
(0.53)\end{array}$ & $\begin{array}{l}-2.17 \\
(1.03)\end{array}$ & $\begin{array}{c}1.17 \\
(0.92)\end{array}$ \\
\hline Services & -0.63 & $\begin{array}{l}-1.55 \\
(0.68)\end{array}$ & $\begin{array}{l}-1.47 \\
(0.77)\end{array}$ & $\begin{array}{l}-1.87 \\
(1.35)\end{array}$ & $\begin{array}{l}-1.62 \\
(1.23)\end{array}$ & $\begin{array}{c}0.13 \\
(0.29)\end{array}$ \\
\hline \multicolumn{7}{|c|}{ Profit function approach (Instrumented Prices) } \\
\hline NFC Private & -1.27 & $\begin{array}{l}-0.41 \\
(3.92)\end{array}$ & $\begin{array}{c}-3.29 \\
(4.92)\end{array}$ & $\begin{array}{l}-0.77 \\
(0.59)\end{array}$ & $\begin{array}{l}-0.30 \\
(1.69)\end{array}$ & $\begin{array}{l}-0.53 \\
(3.36)\end{array}$ \\
\hline Manufacturing & 0.21 & $\begin{array}{l}-0.23 \\
(0.34)\end{array}$ & $\begin{array}{l}-0.20 \\
(0.64)\end{array}$ & $\begin{array}{c}0.17 \\
(0.66)\end{array}$ & $\begin{array}{c}2.90 \\
(1.44)\end{array}$ & $\begin{array}{l}-2.54 \\
(0.80)\end{array}$ \\
\hline Services & -0.63 & $\begin{array}{c}0.26 \\
(0.29)\end{array}$ & $\begin{array}{c}1.04 \\
(0.41)\end{array}$ & $\begin{array}{c}0.30 \\
(0.75)\end{array}$ & $\begin{array}{c}1.34 \\
(1.06)\end{array}$ & $\begin{array}{c}0.07 \\
(0.48)\end{array}$ \\
\hline
\end{tabular}

Notes:

a Standard deviations in parentheses.

b Observed value

It should be noted that the cost and profit models are not designed to, specifically, explain trends in labor productivity growth. Even if duality theory tells us that the parameters of the cost and profit models are intimately related to the structure of production, the fact that these models do yield accurate predictions both over a part of 
the sample and when comparing parts of the sample is rather remarkable. These are fairly demanding diagnostic checks on the quality of the empirical model, and these models hold up well. It is in the decomposition that the models fail to indicate whether public capital has had an impact on labor productivity growth. This is symptomatic, and a consequence, of a high degree of multicollinearity in the data.

Another implication of interest concerns the implied Allen partial elasticity of substitution among the various inputs. Because public capital is a fixed input, the elasticities are nonstandard expressions derived from the cost and profit functions. Formulae are found in Appendix $\mathrm{C}$ and are evaluated at the variables' mean value. While the estimated elasticities lack precision and thus should be interpreted with caution, Table 4 suggests that ( $i$ ) state and federal public capital are substitutes for each other; and (ii) labor is a substitute for public capital; and (iii) private capital is a substitute for federal public capital (and for private labor). In other words, increasing the provision of federal capital relieves the burden of the states, costs jobs, and crowds out private investment.

\section{TABLE 4}

Estimated Elasticities of Substitution ${ }^{\text {a }}$

\begin{tabular}{|c|c|c|c|c|c|c|}
\hline \multirow[b]{2}{*}{ Elasticity } & \multicolumn{3}{|c|}{ Cost Function Approach } & \multicolumn{3}{|c|}{ Profit Function Approach } \\
\hline & NFC Private & Manufacturing & Services & NFC Private & Manufacturing & Services \\
\hline \multicolumn{7}{|c|}{ Aggregated Public Capital Model } \\
\hline \multirow[t]{2}{*}{$e_{L K}$} & 0.72 & 0.82 & 0.55 & 0.18 & 2.38 & 0.17 \\
\hline & $(0.16)$ & $(0.27)$ & $(1.37)$ & $(0.44)$ & $(9.76)$ & $(0.21)$ \\
\hline \multirow{2}{*}{$e_{L G}$} & -0.00 & -0.00 & -0.00 & 0.01 & 1.22 & 0.05 \\
\hline & $(0.00)$ & $(0.00)$ & $(0.00)$ & $(0.02)$ & $(4.81)$ & $(0.09)$ \\
\hline \multirow[t]{2}{*}{$e_{K G}$} & 0.00 & -0.00 & -0.00 & 0.27 & 9.25 & -1.04 \\
\hline & $(0.00)$ & $(0.00)$ & $(0.00)$ & $(1.06)$ & $(34.99)$ & $(0.74)$ \\
\hline \multicolumn{7}{|c|}{ Disaggregated Public Capital Model } \\
\hline \multirow[t]{2}{*}{$e_{L K}$} & -10.65 & 2.15 & -2.85 & 0.70 & 0.35 & -0.83 \\
\hline & $(52.70)$ & (2.68) & (6.59) & $(0.89)$ & $\mathrm{b}$ & (9.34) \\
\hline \multirow[t]{2}{*}{$e_{L G f}$} & 0.24 & -0.17 & 0.49 & 0.21 & 0.03 & 0.75 \\
\hline & $(0.62)$ & $(2.53)$ & $(0.53)$ & $(0.90)$ & $(82.20)$ & (7.15) \\
\hline \multirow[t]{2}{*}{$e_{L G s}$} & -6.69 & 1.61 & 0.74 & 0.43 & 0.08 & 1.55 \\
\hline & $(39.20)$ & (1.27) & $(0.52)$ & $(0.87)$ & $\mathrm{b}$ & (8.79) \\
\hline \multirow[t]{2}{*}{$e_{K G f}$} & 3.28 & 6.01 & 4.61 & 1.87 & -0.54 & 0.10 \\
\hline & (2.94) & (12.72) & (11.82) & (3.81) & $\mathrm{b}$ & (16.15) \\
\hline \multirow[t]{2}{*}{$e_{K G s}$} & 34.28 & -2.83 & -1.55 & 0.92 & -1.56 & 2.95 \\
\hline & $\mathrm{b}$ & (6.33) & (12.29) & $(2.43)$ & $\mathrm{b}$ & (25.98) \\
\hline \multirow{2}{*}{$e_{G s G f}$} & 1.20 & 1.18 & 1.13 & 0.08 & -0.14 & -2.31 \\
\hline & $(0.07)$ & $(0.08)$ & $(0.04)$ & $(0.91)$ & $\mathrm{b}$ & (18.34) \\
\hline
\end{tabular}

Notes:

a Standard deviation in parentheses.

b Value exceeds 100.

Finally, some of the growth theory literature assumes constant returns to scale in capital [Barro, 1991; Rebelo, 1991]. Table 5 shows the estimated percentage growth in output when both private and public capital grows by one percent. The returns to scale derived from the cost function are close to unity, considering the associated standard errors, though effects are smaller in manufacturing and larger in services. The profit function results are not consistent with a notion of constant returns to 
scale in capital, a result that owes to negative returns to public capital as was already shown in Table 1.

TABLE 5

Returns to Scale in Capital

\begin{tabular}{llccrrrr}
\hline \multirow{2}{*}{ Model } & Type of & \multicolumn{2}{c}{ NFC Private } & \multicolumn{2}{c}{ Manufacturing } & \multicolumn{2}{c}{ Services } \\
Cost & Public Capital & R.t.s & (St.dev.) & R.t.s. & (St.dev.) & R.t.s. & (St.dev.) \\
& Aggregate & 0.98 & $(0.27)$ & 0.79 & $(0.35)$ & 1.43 & $(0.45)$ \\
\multirow{3}{*}{ Profit } & Disaggregate & 1.00 & $(0.30)$ & 0.69 & $(0.35)$ & 1.76 & $(0.54)$ \\
& Aggregate & -0.27 & $(0.29)$ & -0.20 & $(0.23)$ & -0.13 & $(0.19)$ \\
& Disaggregate & 0.05 & $(0.45)$ & -0.57 & $(135.83)$ & 0.09 & $(1.24)$ \\
\hline
\end{tabular}

Note: R.t.s. denotes returns to scale.

\section{CONCLUSION}

Just as many other studies before [Gramlich, 1994], we find a large public capital effect: estimates of the rate of return range from -48 to 101 percent for federal public capital, and from -68 to 314 percent for state public capital. Cost function models indicate that investments in public capital enhance labor productivity, but profit function models fail to find an effect that is positive and statistically different from 0 . As a result, cost function models (but not profit function models) suggest that declining investments in public capital caused at least a portion of the slowdown in labor productivity growth in the 1970s; however, these results are not clear about the relative importance of federal or state public capital in this. We also estimate Allen partial elasticities of substitution (which, due to the fixed nature of public capital, are nonstandard expressions): they imply that the provision of federal capital substitutes for efforts by the states, costs jobs, and crowds out private investment. Finally, cost function (but not profit function) results uphold the notion of constant returns to scale in capital, as sometimes assumed in the growth literature.

Since cost and profit function results differ, should one set of results perhaps be preferred over the other? A cost function is closely related to the physical process of production. In principle, profits also depend on the demand characteristics and the structure of the output market, but to account for the endogeneity of output, note that the empirical implementation of the profit function model assumes competitive output markets, as does the cost function model. There are therefore no theoretical grounds for preferring one model to the other. But there is one practical argument: since profit is the difference between revenue and cost and therefore is impacted by random disturbances in both variables, the profit variable may be noisier than the cost variable. If so, the profit function estimates would be less reliable than those of the cost function. The cost function model does indeed yield more plausible results. Some may view this as a strong enough foundation for firm conclusions and rigorous policy recommendations; we would like to see confirmation in further research.

Moreover, these results represent point estimates only and should be treated with great caution. Whereas other studies did not quantify the precision of their estimate, we find that there is a high degree of uncertainty in the exact magnitude of these findings. We examine the issue by means of several data sets that cover a longer period than other studies in the field, two conventional microeconomic models, attention 
to the endogeneity of prices, and a battery of diagnostic tests. Statistically, public capital matters as effects are different from zero; economically, the estimates are not particularly robust, primarily due to a high degree of multicollinearity in the data. Therefore, echoing Vijverberg, Vijverberg and Gamble [1997], our estimates suggest that it will be difficult to arrive at a consensus about the effect of public capital on the basis of this line of research on time series data.

One standard solution to multicollinearity is to collect more data, especially data of a different nature. In principle, utilizing sectoral data is an implementation of this strategy. Moreover, one might argue that the manufacturing and service sectors should not be aggregated since they are governed by different production processes, thus biasing any aggregative analysis. But while sectoral analysis could have led to a different outcome, in the end the conclusion is unchanged. It may still be beneficial to build data sets with more variation in the explanatory variables, such as crossregion/state or cross-industry panel data, or to investigate the contribution of the various components of public capital [Garcia-Mila, McGuire and Porter, 1996; Fernald ,1999; Demetriades and Mamuneas, 2000; Rovolis and Spence, 2002]. One might note as well that studies in this field, like ours, incorporate one specific external factor, which is public capital, while ignoring so many others that may also have an impact, such as regulation, environmental concerns, globalization, computer technology, and changing labor force demographics. ${ }^{24}$ Even so, to measure the impact of public capital on productive activities is clearly important: because of its policy potential, the issue should still hold the profession's attention.

\section{APPENDIX A DATA SOURCES}

The following sources are used to compile the data, with the acronyms to be used below:

BCD: $\quad$ Business Conditions Digest. Bureau of Economic Analysis, U.S. Department of Commerce, Washington, D.C. August 1988.

ER: $\quad$ Economic Report of the President. U.S. Government Printing Office. Washington, D.C. 1995, 2000 (w3.access.gpo.gov/eop/).

BLS: $\quad$ Bureau of Labor Statistics (www.bls.gov/data/home.htm)

BEA: $\quad$ Fixed Assets Tables; Bureau of Economic Analysis (www.bea.doc. gov/bea/dn/faweb). For more information, see also Katz and Herman [1997].

RR: $\quad$ Romer and Romer [1990; 1994].

The data are annual and cover the period from 1959 through 2000 for the nonfinancial corporate private sector data and for the manufacturing sector, and 1965 to 2000 for the service sector. The service sector consists of wholesale trade, retail trade, and 'services' as officially defined as a separate category. As discussed in the section on Data and Estimation Issues, the usually included subsectors of finance, insurance, and real estate are omitted.

- $\quad L=$ hours worked. 
Private sector: defined as the constant (1996) dollar value of corporate nonfinancial GDP [ER, 2002, B-14] divided by output per hour of all employees in 1996 dollars. The latter is computed from the 1987 value given in [ER, 1995, B-14], transformed to 1996 prices with the variable $p_{Q}$ given below, and computed for other years by means of information on the percentage change in output per hour in the nonfarm business sector [ER, 2002, B-50]. Manufacturing: hours worked by production workers, defined as (production-worker average weekly hours + production-worker average weekly overtime hours) * 52 weeks * total number of production workers [BLS]. Services: hours worked by production workers, defined as production-worker average weekly hours * 52 weeks * total number of production workers [BLS].

- $\quad p_{L}=$ compensation per hour of work in current dollars.

Private sector: series from 1959 to 1993 [ER, 1995, B-14], extended by means of changes in the total compensation cost index covering the entire private sector [ER, 2002, B-48]. Manufacturing: average hourly earnings in current dollars of production workers [BLS], multiplied with the ratio of total compensation in the nonfinancial private sector over wages in the private nonagricultural industries [ER, 2002, B-47]. Services: average hourly earnings of production workers [BLS], multiplied with the ratio of total compensation in the nonfinancial private sector over wages in the private nonagricultural industries [ER, 2002, B-47].

- $\quad K=$ constant (1996) dollar net stock of capital.

Private sector: corporate nonfinancial fixed nonresidential private capital (equipment and structures). [BEA, Tables 4.1; 4.2]. Manufacturing and services: fixed nonresidential private capital (durable and nondurable goods). [BEA, Tables 3.1ES; $3.2 \mathrm{ES}]$.

- $\quad p_{K}=q_{K}(r+d)-\Delta q_{K}=$ user cost of capital.

$q_{K}$ is the current nominal price of capital goods, $r$ is the nominal interest rate, $d$ is the depreciation rate, and $\Delta q_{K}$ is the change in the price of capital goods. $q_{K}$ is the ratio of the current to constant (1996) dollar net stock of capital as defined above. [BEA: Current value: private sector: Tables 4.1; manufacturing and services: Tables 3.1ES]. $r$ is Moody's Aaa corporate bond rate [ER, 2002, B-73]. $d$ is measured for all three samples as the current dollar value of the capital consumption allowance divided by the current dollar value of the net stock of corporate nonfinancial fixed nonresidential private capital (equipment and structures). [ER, 2002, B-14; BEA, Table 4.1]. In two cases where $p_{K}$ turned out to be a tiny negative value, it was arbitrarily set equal to 0.005 which was smaller than the smallest positive value in the remainder of the three datasets.

- $\quad Q=$ constant (1996) dollar value of output. 
Private sector: GDP of nonfinancial corporate business [ER, 2002, B-15]. Manufacturing and services: nominal sectoral GDP [ER, 2002, B-12] divided by $p_{Q}$.

- $\quad p_{Q}=$ price of output.

Ratio of nominal to real dollar value of output. Private Sector [ER, 2002, B-15]. Manufacturing and Services: spliced together from [ER, 1991, B-10; B-11; 1999, B12; B-13; 2002, B-12; B-13]; see footnote 4 in the section on Data and Estimation Issues.

- $\quad G_{f}=$ federal public capital.

Constant dollar net stock of federal, nonmilitary government-owned fixed capital (equipment and structures) in 1996 dollars. [BEA, Tables 7.1; 7.2].

- $G_{s}=$ state public capital.

Constant dollar net stock of state and local government-owned fixed capital (equipment and structures) in 1996 dollars. [BEA, Table 7.1 and 7.2].

- $G=$ public capital, defined as $G_{f}+G_{s}$

- $t=$ linear time trend, starting with 1 in the first year of the sample.

The following are used as instruments:

- $\quad$ Federal Funds Rate [ER, 2002, B-73].

- $\quad$ Exports: constant dollar U.S. exports [ER, 2002, B-6].

- Defense Expenditures: constant dollar federal government purchases of goods and services for national defense [ER, 2002, B-6].

- $\quad$ Romer dates: dates at which monetary policy changed into a substantially more restrictive stance: December 1968, April 1994, August 1978, October 1979, and December 1988. To annualize, we assume an exponential decay of the shock with a 95 percent rate of completion after seven months [RR].

\section{APPENDIX B \\ ESTIMATES OF MODELS WITH DISAGGREGATE PUBLIC CAPITAL AND INSTRUMENTED PRICES}

Table A1 and A2 present estimates of the cost and profit function models specified with disaggregate public capital and instrumented prices. Likelihood ratio test statistics should be compared with a $\chi_{0.05}^{2}(6)=12.59$ critical value: public capital enters 
in a statistically significant way only in the cost function model of the manufacturing and service sectors and the profit function model of the nfc private sector.

TABLE A1

FIML Estimates of the Cost Function Model with

Disaggregated Public Capital

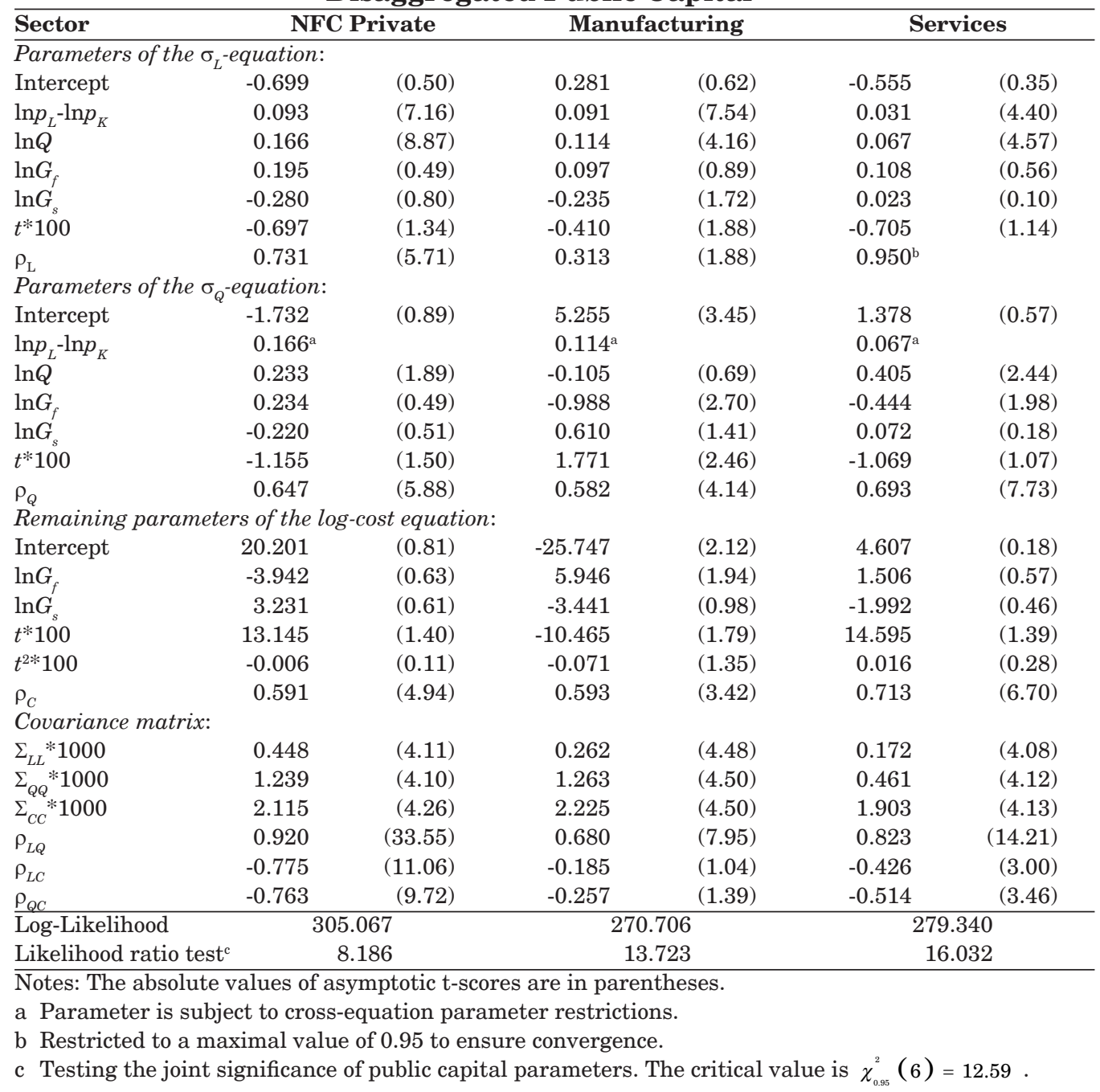

\section{APPENDIX C DERIVING ELASTICITIES OF SUBSTITUTION AND RETURNS}

Define the Allen partial elasticity of substitution as $\theta_{i j}=H_{i j}\left(\sum_{k} F_{k} X_{k}\right) /\left(H X_{i} X_{j}\right)$, where $H$ is the determinant of the bordered Hessian matrix of the production function $F, H_{i j}$ is the cofactor associated with $F_{i j}$, and $X$ is the input vector consisting of $L$, $K, G_{f}$, and $G_{s}$. This appendix presents the formulae needed to extract values for the production function derivatives $F_{i j}$ from the dual functions $C$ and $\Pi$. This procedure is nonstandard since $G_{f}$ and $G_{s}$ are treated as fixed inputs. 
TABLE A2

FIML Estimates of the Profit Function Model with Disaggregated Public Capital

\begin{tabular}{|c|c|c|c|c|c|c|}
\hline \multirow{2}{*}{\multicolumn{2}{|c|}{$\begin{array}{l}\text { Sector } \\
\text { Parameters of the } s_{Q} \text {-equation: }\end{array}$}} & ivate & \multicolumn{2}{|c|}{ Manufacturing } & \multicolumn{2}{|c|}{ Services } \\
\hline & & & & & & \\
\hline Intercept & -40.891 & $(0.61)$ & 18.940 & $(1.52)$ & 2.033 & $(0.05)$ \\
\hline $\ln p_{Q}-\ln p_{K}$ & -8.778 & $(0.42)$ & -5.442 & (6.18) & -6.719 & $(5.12)$ \\
\hline $\ln p_{L}-\ln p_{K}$ & 6.934 & $(0.40)$ & 5.205 & (6.11) & 6.499 & $(4.92)$ \\
\hline $\ln G_{f}$ & 7.531 & $(0.35)$ & 0.434 & $(0.21)$ & -0.450 & $(0.16)$ \\
\hline $\ln G_{s}$ & -3.485 & $(0.11)$ & 1.473 & $(0.86)$ & -2.342 & $(0.57)$ \\
\hline$t^{s}$ & -0.342 & $(0.83)$ & -0.187 & $(3.18)$ & 0.009 & $(0.06)$ \\
\hline$\rho_{Q}$ & 0.382 & $(1.42)$ & $0.950 \mathrm{a}$ & & 0.730 & $(4.78)$ \\
\hline \multicolumn{7}{|c|}{ Parameters of the $\left(-s_{L}\right)$-equation: } \\
\hline Intercept & 22.045 & $(0.49)$ & 14.639 & (1.54) & 0.309 & $(0.01)$ \\
\hline $\ln p_{Q}-\ln p_{K}$ & $6.934 \mathrm{~b}$ & & $5.205 b$ & & $6.499 \mathrm{~b}$ & \\
\hline $\ln p_{L}-\ln p_{K}$ & -5.744 & $(0.35)$ & -5.145 & (6.06) & -6.363 & (4.79) \\
\hline $\ln G_{f}$ & -3.858 & $(0.27)$ & -0.501 & $(0.29)$ & 0.462 & $(0.20)$ \\
\hline $\ln G_{s}^{\prime}$ & 2.256 & $(0.11)$ & -0.275 & $(0.20)$ & 2.078 & $(0.63)$ \\
\hline$t$ & 0.222 & $(0.76)$ & 0.160 & (3.52) & -0.002 & $(0.02)$ \\
\hline$\rho_{L}$ & $0.382 \mathrm{c}$ & & $0.950 \mathrm{c}$ & & $0.730 \mathrm{c}$ & \\
\hline \multicolumn{7}{|c|}{ Remaining parameters of the log-profit equation: } \\
\hline Intercept & 8.764 & $(0.12)$ & 12.699 & $(0.72)$ & 29.415 & $(0.54)$ \\
\hline $\ln G_{f}$ & -1.200 & $(0.07)$ & -1.215 & $(0.31)$ & -2.646 & $(0.53)$ \\
\hline $\ln G_{s}^{\prime}$ & 0.183 & $(0.01)$ & -1.745 & $(0.51)$ & -4.099 & $(0.95)$ \\
\hline$t$ & -0.083 & $(0.27)$ & -0.125 & $(1.35)$ & 0.072 & $(0.34)$ \\
\hline$t^{2 *} 100$ & -0.666 & $(0.53)$ & -0.506 & $(3.66)$ & -0.108 & $(1.59)$ \\
\hline \multicolumn{6}{|l|}{ Covariance matrix: } & $(2.62)$ \\
\hline$\Sigma_{Q Q}$ & 55.819 & $(4.55)$ & 0.051 & $(4.28)$ & 0.011 & $(3.94)$ \\
\hline$\Sigma_{L L}$ & 25.522 & $(4.56)$ & 0.022 & $(4.25)$ & 0.006 & $(4.06)$ \\
\hline$\Sigma_{\Pi \Pi}$ & 0.113 & (4.08) & 0.006 & (3.97) & 0.002 & $(4.00)$ \\
\hline$\rho_{Q L}$ & -0.999 & d & -0.975 & d & -0.970 & $(90.26)$ \\
\hline$\rho_{Q \Pi}$ & -0.934 & $(36.84)$ & -0.839 & $(14.75)$ & -0.781 & $(9.44)$ \\
\hline$\rho_{L \Pi}$ & 0.931 & $(34.42)$ & 0.811 & (12.50) & 0.823 & (12.86) \\
\hline Log-Likelihood & & & & & & \\
\hline Likelihood ratio test ${ }^{e}$ & & & & & & \\
\hline
\end{tabular}

Notes: The absolute values of asymptotic t-scores are in parentheses.

a Restricted to a maximal value of 0.95 to ensure convergence

b Parameter is subject to cross-equation parameter restrictions.

c Restricted in order to preserve the adding-up constraint.

d t-score exceeds 100.

e Testing the joint significance of public capital parameters. The critical value is $\chi_{0.95}^{2}(6)=12.59$.

To simplify the formulae under the cost function approach, define $I=(L K)^{\prime}$ as the variable input vector and $w=\left(p_{L} p_{K}\right)^{\prime}$ as its price vector. Let $G=\left(G_{f} G_{s}\right)^{\prime}$. Thus, $X=\left(I^{\prime} G^{\prime}\right)^{\prime}$. The cost function $C(w, Q)$ is found by minimizing $C=w^{\prime} I$ subject to the restriction $Q=F(I, G)$. Let $\lambda$ be the Lagrange multiplier of the restriction. The input demand functions are stated in general terms as $I=I(w, G, Q)$, with its derivatives derived in standard ways from the first order conditions of minimization; the expressions contain second order derivatives of the production function multiplied with $\lambda$. If the cost function is first specified, one has the result $\partial C / \partial w=C_{w}=I$. Thus, the derivatives of the input demand functions depend on second-order derivatives of C. Specifically, 


$$
\begin{gathered}
\lambda F_{I I}=\left(C_{w w}-C_{w Q} C_{Q Q}^{-1} C_{w Q}\right)^{-1} \\
\lambda F_{I G}=-C_{w w}^{-1} C_{w G}+C_{w w}^{-1} C_{w Q} \frac{C_{G}^{\prime}}{C_{Q}} \\
\lambda F_{G G}=-C_{G G}-\frac{C_{Q Q}}{\left(C_{Q}\right)^{2}} C_{G} C_{G}^{\prime}+C_{w G}^{\prime} C_{w w}^{-1} C_{w G}-\frac{C_{G}}{C_{Q}} C_{w Q}^{\prime} C_{w w}^{-1} C_{w Q} \frac{C_{G}^{\prime}}{C_{Q}}
\end{gathered}
$$

where $C_{w w}=\partial^{2} C / \partial w \partial w^{\prime}$, etc. Furthermore, $F_{G}=-C_{G} / C_{Q}, F_{I}=w / C_{Q}$, and, in a competitive economy, $C_{Q}=\lambda=p_{Q}$. With this information, the elasticities of substitution can be computed.

To simplify the formulae needed under the profit function approach, define $I=(L K)^{\prime}$ and $w=\left(p_{L} p_{K}\right)^{\prime}$. The dual profit function is stated in general terms as $\Pi=\Pi\left(p_{Q}, w, G, t\right)$, which is the outcome of the maximization of $\Pi=p_{Q} Q-w^{\prime} I$, subject to the restriction $Q=F(I, G, t)$. Similar to above, the derivatives of the input demand functions can be stated in terms of second order derivatives of $F$ as well as П. Thus,

$$
\begin{gathered}
I=-\Pi_{w} \\
F_{I}=-\Pi_{w w}^{-1} \Pi_{w p} \\
F_{G}=\Pi_{G} / p_{Q} \\
F_{I I}=-\Pi_{w w}^{-1} / p_{Q} \\
F_{I G}=-\Pi_{w w}^{-1} \Pi_{w G} / p_{Q} \\
F_{G G}=\left(\Pi_{G G}-\Pi_{w G}^{\prime} \Pi_{w w}^{-1} \Pi_{w G}\right) / p_{Q}
\end{gathered}
$$

Second-level subscripts on $p_{Q}$ are omitted.

The return to investments in public capital is given by $F_{G}$; the expressions have already been used above.

\section{NOTES}

We gratefully acknowledge the helpful comments of an anonymous referee.

1. With a panel of industry data and a completely different empirical model, Fernald [1999] illustrates the contribution of road-building in the 1950s and 1960s.

2. Morrison and Schwarz [1996] found that investment in public (infrastructure) capital lowers costs in the manufacturing sector but also that the rate of return net of the cost of investment is close to zero.

3. Unlike Lynde and Richmond [1993] and Vijverberg, Vijverberg, and Gamble [1997], we do not consider material inputs here, as sectoral data on material inputs do not exist. The latter study, which used aggregate data, did not indicate that raw materials had an important effect. 
4. The intuition behind this result is that an increase in $G$ raises output by an amount of $F_{G}$. Under cost minimization, the firm aims for an output target $Q$. The increase in $G$ therefore allows the firm to reduce its use of inputs equal to the value of the output generated by $d G$ (because of the competitive output market assumption).

5. Consistent with what was mentioned earlier in the text, $\Gamma_{G G}=\Gamma_{G t}=\Gamma_{t G}=0$.

6. Given the short length of the sample ( $N$ ranging from 36 to 42 ) and the number of parameters in the $\ln C$ equation (12 or 15, and a serial correlation parameter), we actually have little choice but to impose the cross-equation parameter restrictions. If the iterative search for parameter estimates converges for the unrestricted model, there is still the question by what distribution one would evaluate the implied likelihood ratio test statistic, since the sample is so small.

7. The missing years for the service sector owe to missing information on wages and total hours worked in the (officially denoted) service subsector, which in fact was created as a result of a reorganization of data collection methods in the early 1960s. In the late 1980s, SIC codes were changed which may have some impact on the continuity of the sectoral data, but implausible discontinuities are not evident. The difference in years covered might account for some of the sectoral variation in the estimation results.

8. The 2000 value of (nonfinancial corporate) private sector output (in 1982 dollars) was $\$ 5380.7$ billion; that of all private sectors combined was $\$ 8356.8$ billion, of which the manufacturing and service sector (as defined here) contributed $\$ 5299.2$ billion; the finance, insurance, and real estate subsectors generated another $\$ 1936.2$ billion. Similarly, consider capital stock values: in 2000 , the nonfinancial corporate private sector had a stock (in 1996 dollars) valued at $\$ 6804$ billion out of a total of $\$ 12181$ billion of private sector fixed capital; the manufacturing and services sectors had $\$ 3914$ worth of capital, whereas among the other sectors nonresidential real estate took the lion's share with $\$ 3407$ billion and transportation and utilities contributed $\$ 2637$ billion.

9. Endogeneity of prices is not incongruous with the perfect competition assumption made in the second section: perfect competition relates to the behavior of firms; endogeneity of prices relate to the behavior of markets.

10. The instrumental equations predict quite well, but it should be remembered that in time series models, where high $R^{2}$-values are common, slight variations can be very meaningful. For example, adding one variable to a model may raise the $R^{2}$ from 0.95 to 0.96 , which seems to be a trivial improvement until one realizes that this one variable explain one fifth of the remaining unexplained variation in the dependent variable. In the context of the IV technique, the predicted prices remove a small but, based on one's trust in the instrument variables, important endogenous component from the prices variables, which can have a substantial impact on the results.

11. It is a bit surprising that even the labor and output share/ratio variables are found to be nonstationary. But recall that in these tests the Null hypothesis posits the existence of a unit root. These kinds of test statistics have weak power in short time series when variables are serially correlated but do not have a unit root. Thus, as plausible as the notion of stationarity is, there is not enough information in the data to reject the base idea of nonstationarity.

12. We compared the autocorrelation and partial autocorrelation functions of the residuals with the behavior (under the same sample size) of 100 simulated variables with a unit root and used the least unit-root-like behavior as a minimal guideline.

13. A simplified model omits the cost or profit equation and merely estimates share equations. It turns out that the residuals of these share equations also exhibit nonstationarity, contrary to a similar study by Lynde and Richmond [1993]. Thus, entering a cost or profit equation into the model is not a cause for an apparent lack of cointegration.

14. Tables with the parameter estimates for the instrumented models and disaggregated public capital are given in Appendix B. The contribution of public capital is represented by six parameters, estimates of which may be individually statistically insignificant even when the group together is statistically significant. A cursory inspection of the parameter estimates reveals that this indeed happens, possibly owing to multicollinearity or overparameterization.

15. We also experimented with a one-period lag on $G$. Results were similar. It is not a priori clear how long the lag should be, if there should be one.

16. To be sure, the literature has not yet generated a "typical" estimate of returns against which our estimates can be compared. Literature using the production function approach [Aschauer, 1989; others] suggests a rate of return of up to 100 percent, which is very high indeed [Gramlich, 1994]. 
Morrison and Schwartz [1996] used the cost function approach to estimate the shadow values of state infrastructure of manufacturing firms and generated returns ranging from 5.6 percent to 34.9 percent. Our study corresponds with these results but does not manage to narrow the range. Better estimation techniques yield numerically different estimates of the return that, econometrically, should be qualitatively superior. The characteristics of the data prevent these estimates from showing up qualitatively superior in an economic sense: multicollinearity is so extreme that a more precise estimate of the return to public capital investment remains elusive. At the same time, our public capital variable refers to an aggregate, and it may be that one may be able to estimate rates of return more precisely for its components [Gramlich, 1994, 1178].

17. Alternatively, one might wish to formulate an error correction model [Hamilton, 1994, chap. 19], but this is not a feasible strategy. An error correction model is a restricted version of a general linear vector autoregression model, where linear combinations of nonstationary variables are stationary and influence the path of each separate nonstationary variable through error correction parameters. An error correction model starts with a set of non-stationary variables, presupposes a linear structure, and hopes to discover economically meaningful structures. The complexity of a three-equation nonlinear model with cross-equation parameter restrictions goes far beyond what the error correction model was designed for. Cost and profit function models start with a quadratic structure. A non-stationary variable integrated of order 1 may become part of a cointegrated linear system, but this same variable squared has radically different statistical properties, making it statistically inconsistent with the notion of a cointegrated system in the form that the literature has studied. Finally, an attempt to implement an error correction model would presumably add nine error correction parameters to be estimated (three for each equation), putting added pressure on the limited amount of data available here: with roughly 40 years of data, we already estimate 21 parameters. One might note that the share equations are linear and therefore amenable to an error correction estimation strategy [Oniki 2000], or that the simplicity of the share equations may make the residuals more appropriate for the ADF, $Z_{\rho}$ and $Z_{t}$ tests [Lynde and Richmond, 1992; Clark and Youngblood, 1992]. This strategy yields estimates of some but not all of the translog model parameters, and it evades the translog structure that ties the share equations to the cost or profit equation.

18. Note that differencing a nonstationary variable (say, $x$ ) yields a stationary variable $\Delta x$ only if $x$ is integrated of order 1 . By implication, since the model contains linear, quadratic and interacted variables, estimating the model in difference form is not guaranteed to produce a set of stationary residuals, as the variation in results for cost and profit models demonstrates.

19. Differenced data elicit short-run effects, but with a lack of cointegration one would still wish to formulate an error correction model. As in footnote 17, that is not a feasible strategy here either.

20. The cost function and profit function models are highly nonlinear, with many cross-equation parameter restrictions implied. Test statistics may be computed but are compared with flawed approximations to the true underlying distributions.

21. Mathematically, this is expressed in equations (5) and (8) in the second section.

22. Or 1965-1973 in case of the service sector, owing to data limitations.

23. It should be noted that, contrary to the variability of the contribution of public capital and the time trend, the implied impacts of changes in the capital/labor ratio and in the size of the labor force are nearly identical across the four sets of results for each sector. The impact of the capital/labor ratio is $0.17,0.33$ and 0.15 for the nfc private, manufacturing and service sectors respectively; the impact of the labor force growth is $-0.35,0.04$ and -0.83 , respectively. In particular, the last statistic shows that the labor productivity growth rate in the service sector has been depressed by the sector's rapid labor force growth.

24. One might also consider the movement from manufacturing to services production in the economy as a factor driving the change in labor productivity. By separately estimating models for the manufacturing and service sectors, we in fact control for this factor.

\section{REFERENCES}

Aschauer, D. Is Public Expenditure Productive? Journal of Monetary Economics, March 1989 177-200.

Barro, R. Government Spending in a Simple Model of Endogenous Growth. Journal of Political Economy, October 1990, S103-S125. 
Berndt, E. and Savin, E. Estimation and Hypothesis Testing in Singular Equation Systems with Autoregressive Disturbances. Econometrica, September 1975, 937-957.

Clark, S. and Youngblood, C. Estimating duality models with biased technical change: a time series approach. American Journal of Agricultural Economics, May 1992, 353-360

Davidson, R. and MacKinnon, J. Estimation and Inference in Econometrics. New York: Oxford University Press, 1993.

Demetriades, P. and Mamuneas, T. Intertemporal Output and Employment Effects of Public Infrastructure Capital: Evidence from 12 OECD Economies. Economic Journal, July 2000, 687-712.

Deno, K. The Effect of Public Capital on U.S. Manufacturing: 1970 to 1978. Southern Economic Journal, October 1988, 400-411.

Elliott, G., Rothenberg, T. and Stock, J. Efficient Tests for an Autoregressive Unit Root. Econometrica, July 1996, 813-836.

Fernald, J. Roads to Prosperity? Assessing the Link Between Public Capital and Productivity. American Economic Review, June 1999, 619-638.

Garcia-Mila, T., McGuire, T. and Porter, R. The Effect of Public Capital in State-Level Production Functions Reconsidered. Review of Economics and Statistics, February 1996, 177-180.

Gramlich, E. Infrastructure Investment: A Review Article. Journal of Economic Literature. September 1994, 1176-1196.

Hamilton, J. Time Series Analysis. Princeton: Princeton University Press, 1994.

Katz, A. and Herman, S. Improved Estimates of Fixed Reproducible Tangible Wealth, 1929-1995. Survey of Current Business. May 1997, 69-76.

Lynde, C. and Richmond, R. The Role of Public Capital in Production. Review of Economics and Statistics, February 1992, 37-44.

Public Capital and Total Factor Productivity. International Economic Review, May 1993, 401-414.

Morrison, C., and Schwartz, A. State Infrastructure and Productive Performance. American Economic Review, December 1996, 1095-1111.

Munnell, A. Why Has Productivity Growth Declined? Productivity and Public Investment. New England Economic Review, January/February 1990, 3-22.

Oniki, S. Testing the induced innovation hypothesis in a cointegrating regression model. Japanese Economic Review, December 2000, 544-554.

Phillips, P. and Ouliaris S. Asymptotic Properties of Residual Based Tests for Cointegration. Econometrica, January 1990, 165-193.

Ram, R. and Ramsey D. Government Capital and Private Output in the United States. Economics Letters, September 1989, 223-226.

Ratner, J. Government Capital and the Production Function for U.S. Private Output. Economics Letters, March 1983, 213-217.

Rebelo, S. Long-Run Policy Analysis and Long-Run Growth. Journal of Political Economy, June 1991, 500-521.

Romer, C. and Romer D. New Evidence on the Monetary Transmission Mechanism. Brookings Papers on Economic Activity, vol. 1, 1990, 149-213. Monetary Policy Matters. Journal of Monetary Economics, August 1994, 75-88.

Rovolis, A. and Spence S. Duality Theory and Cost Function Analysis in a Regional Context: The Impact of Public Infrastructure Capital in the Greek Regions. The Annals of Regional Science, February 2002, 55-78.

Sturm, J. and De Haan J. Is Public Expenditure Really Productive? Economic Modeling, January 1995, 60-72.

Tatom, J. Public Capital and Private Sector Performance. St. Louis Federal Reserve Bank Review, May/ June 1991, 3-15.

Vijverberg, W, Vijverberg C. and Gamble J. Public Capital and Private Productivity. Review of Economics and Statistics, May 1997, 267-278. 